\title{
Research on Chinese Ancient Design Ethics
}

\author{
Chuangye Ma \\ Huanghe Science and Technology College \\ Zhengzhou, China 450000
}

\begin{abstract}
From the perspective of definition of modern ethics, design ethics belong to a kind of caring ethics and responsibility ethics essentially. The so-called responsibility ethics are the concentrated presentation of moral philosophy in the new technology age. The greatest feature of such ethical view is to transfer the abstract value without concrete direction to a kind of future-oriented values that is really responsible for their own behavioral consequences. Confucian Classical Aesthetic Concepts Integrating "Truth, Goodness and Beauty" Expressed Design Ethics. The main ideas of Mohist ethics that influence China's ancient creation are "valuing practicality", "economical use" and "communication." Taoist thinking is negative and unpretentious. Viewing from the perspective of modern design, Taoist design ethics system is mainly reflected as showing respect for nature.
\end{abstract}

Keywords-Chinese Ancient Ethics; design; Confucian; Mohist; Taoist

\section{INTRODUCTION}

"Ethic refers to various moral principles for the relationship between people. Ethics refers to the theory about the origin and development of morality, people's code of conduct as well as obligations between people"1. The term "ethic" first appeared in The Book of Rites: Music. Zhu Jianmin, an honorary professor of National Central University, thinks that "ethics" is a polysemy, referring to not only a certain kind of normative system, but also refer to the research of such standards. As a kind of special discipline and professional ethics, Marxist philosophy and ethics will inevitably resort to ethics to educate people, making them know what should be done and what should not be done. Just as what Moritz Strock, a famous German philosophy professor mentioned in "Ethical Issues" that ethical issues involve in moral, fashion, and the things considered to be people's code of conduct and norms, or the oldest simple word: goodness. "2

"Design involves extensive fields closely relating to people's lives, or even concerning people's vital interests. From a macro perspective, design ethics refer to the moral law and code of conduct with moral value that shall be followed in design activities, which can balance the relationship of "interest" and "obligation" in design activities, and coordinate the interrelation between design and human, design and society as well as design and nature. From the micro perspective, design ethics runs through the design activities from design scheme, implementation process to completion". "From the perspective of definition of modern ethics, design ethics belong to a kind of caring ethics and responsibility ethics essentially. The so-called responsibility ethics are the concentrated presentation of moral philosophy in the new technology age. The greatest feature of such ethical view is to transfer the abstract value without concrete direction to a kind of future-oriented values that is really responsible for their own behavioral consequences.

Design ethics is not a strange term. In design ethics of modern design, people-oriented nature has been reflected in the design ethics of a variety of practical design, such as "humanized design", "green design", and "ecological design". Research the relationship between people, human and society, human and nature from the long-term interests and the relationship with morality by virtue of the media, to make it more beautiful and harmonious. Design ethics focuses on design science, which mainly discusses those ethical issues need to be noted in design science. Therefore, design ethics requires that "design shall take people's long-term and fundamental interests of mankind as the starting point, consciously cherish the common wealth, preserve natural resources, establish the healthy and scientific human environment, and resist the uncontrolled development, production and consumption that are harmful to human living environment."

\section{CONFUCIAN DESIGN ETHICS}

Reflecting in China's ancient creation design, there are mainly three aspects of design ethics in Confucian thoughts, namely the theme, purpose and style of design, which have regulated the forms of design. This kind of form conforms to the traditional Chinese "benevolent" ethical thought system, which is also effective if applied to the modern design. The benevolence of design mainly refers to the ethical value, ethical standards and spiritual pursuit that involve in design. "Pursuit of benevolence" is the foundation for designers to improve themselves.

\section{A. Confucian Classical Aesthetic Concepts Integrating "Truth, Goodness and Beauty" Expressed Design Ethics}

The design shall reach the acme of perfection. "Beauty" represents the outward expression, and "goodness" is the internal factors generating "beauty". "Confucius said in Shao that doing everything best means the acme of perfection is achieved. And said in $\mathrm{Wu}$ that doing everything best cannot be said the acme of perfection is achieved." Confucius believed that art must have a function of advocating the pursuit of noble moral. Confucian aesthetic ideology is closely related to morality, of which the core is advocating mutual coordination and unity of beauty and goodness, having an extremely wide 
influence in ancient Chinese creation process. The attractive ancient arts and crafts are inseparable from the aesthetic idea integrating "truth, goodness and beauty" advocated by Confucianism. Confucius lays the basis of "beauty" on "goodness" with emphasis. The "goodness" in terms of moral shall become the connotation embodiment of "beauty" of molding objects, and a template type standard for measuring beauty. The profound influence on ancient Chinese creation by esthetic sentiment of Confucian thoughts has laid a very solid foundation for the profound cultural atmosphere existing in the process of ancient Chinese creation. For example, there is such guiding concept of "in urban planning and construction, each of the four sides shall be $9 \mathrm{Li}$, with three doors at left and right sides respectively, nine streets at the horizontal direction and nine at vertical direction with the width of being able to contain nine driving carts simultaneously, the left side is temple, right side is shrine, the front is for courtiers' worship, the backward is the market, both the market and the place for worship are a square with the side of 100 steps" in urban planning and construction. Confucian hopes to nurture and regulate the public's moral awareness through the actual production in daily life. As an important means to influence and educate people's thought, productive labor shall bear "virtue", believing "virtue" is very important in presenting products' design.

\section{B. Influence on Ancient Creation by the Confucian Ethical Idea of "Moderation Is Virtue"}

"It may be the best to be moderation, and that is the reason why it is a virtue" is the Doctrine of the Mean in Confucian thoughts. The thinking methods of "being moderation" in Confucian thoughts is to "fulfill rites". "Rites are to help people do appropriately". "Being moderation is to be polite. Moderation means to follow the ritual system strictly without change, exaggeration or deflection. Such ethical concept is reflected as harmonious beauty in term of aesthetic ideology. It seems that harmonious beauty is the aesthetic view point of Confucianism, but in fact, it is a manifestation of a deeper ethical idea. The beauty of harmony mainly refers to the pursuit of appropriate and reasonable formal sense of beauty in creation styles when reflected in Chinese ancient creation, without extreme, affectation, and grandstanding. For example, the good description of the Ode reflects the idea of harmonious beauty, "It is the best of being upright without arrogance, being winding tiredness, being near yet not forced, being far yet not dissociated, being changed yet not too excessive, bearing responsibility yet not being tired, being sad yet not grieve, being happy yet not dissolute, using yet not exhausting, being wide yet not publicizing, applying without wasting, collecting without corrupting, being stable without stagnation, being popular yet not over excessive. Pentatonic scale makes harmony, octave renders coordination; there is law in beats, and musical instruments are ordered. These are all the characters of people who have good morals. The harmonious and reasonable treatment method is described elaborately, having praised the grasp of the scale and the harmonious and perfect artistic effect. Confucianism thinks that paying attention to moderate harmonious beauty is conducive to the nurture of art audiences in terms of moral level, enabling the appreciator to achieve the unity from spiritual level to psychological level, playing a positive role for the society's harmony and stability.

\section{Influence on Ancient Creation by Confucian Ethics}

Confucian ethics has mentioned "unity of nature and human", and many scholars believe that theory is Taoism. In fact, both of them have this viewpoint, but with different meaning. Confucianism advocates to "regard object as virtue" for the unity of nature and human, for example, "the virtue of gentleman is like wind; the virtue of villain is like grass; the wind over grass must blow across it." However, the original idea of Taoism is to respect the nature. "The theory of "Dao" proposed by Lao Tze, the founder of Taoism, has laid the foundation for worshiping the beauty of nature by Chinese classic aesthetic." It explains the unity of nature and human isolating from the reality. The Confucianism is to foil people using nature, guiding people to achieve the final purpose of human and nature living in harmony by virtue of reasonable behavior through learning from the nature. Artificer's Record proposes the design thought of integrating with nature, which says: "Haven has time, earth has characters, materials have beauty, work has skills, and the good will be made out if the four are gathered." "Heaven has time" refers to the seasonable variations; "earth has characters" means there are differences in geographical conditions: "materials have beauty" refers to material nature's different beauty; "work has skills" means the level of process technique. Only by the combination of these aspects, can the good design works be generated, which is the Confucian design concept.

The ethics of "unity of nature and human" in Chinese ancient design requires paying attention to moral code, to make the design objects not only has the function of being used, but also can exert influence on people's soul through the design, as well as focusing on the emotional communication between design and material selection and users. All the objects carrying morality are qualified to take its place in higher circles. To conduct moral education is Confucian school's important social mission, and the tool for moral education is the creation and design, because in the process of creation, the designer's ethics and ideas are certainly integrated in, and then popularize and enhance the moral level through inheritance of the objects.

\section{MOHIST DESIGN ETHICS}

The main ideas of Mohist ethics that influence China's ancient creation are "valuing practicality", "economical use" and "communication." The important problems of moral construction in modern design ethics have been reflected early in Mohist ethical thoughts. "Valuing practicality" refers to the control of form and function problems in the design process; "economical use" is the reflection of resource saving in design; "communication" is the harmonious treatment of various problems in relationships. Mohist advocates "valuing practicality". There is a saying goes that "clothing shall be able to keep warm and them seek beauty of it; residence shall be safe first of all, and then seek pleasure in it", which mainly refers to the practicality. Practicality is the basic criteria for evaluating an item, which measures the beauty of craftworks. "If a work is beneficial to people, then we can say it is skillful, 
otherwise, we say it clumsy." The design ethics of "valuing practicality" mainly focuses on the problems in form and founction, decoration and practicality with regard to ancient creation. The main viewpoint of Mozi is practicality, and the formation of which is related to the social status of Mozi himself. Mozi belongs to the lower classes at that time, so he mainly considers meeting people's basic living requirements without seeking luxurious, pursuing practicality only. In addition, another important Mohist ethics of ancient creation is "economical use", thinking only to consider the most fundamental use function of the man-made objects, and save social resources to the largest extent. For example, as for the dressing view, "the doctrine for clothing shall be warming up in winter, be cooled in summer, and remove them if none is added." It holds the opinion that the function of clothing is to keep warm in winter, be cool in summer, which is simple and direct. The thought of "economical use" is the important ethical thought reflecting the relationship between human and human, as well as human and nature, which can be said one of the core thoughts of Mohism. Mozi links people's clothing, food, housing, transportation to politics. The necessities of human beings are generated for the ancient ancestors to survive, and the ruler should encourage thrift, to make the country prosperity relying on economy. Mozi is against the extravagance and waste of the nobility, extravagant funeral, reflecting the viewpoints such as "simple funeral", and "nonentertainment". The ethical thought of "economical use" is established based on the understanding of function and decoration. Mozi lays emphasis on basis of functions, and also stresses the "economical" design principle. Finally, explore the "free communication" viewpoint in Mohist design ethics through the influence on China's ancient creation by Mohist ethics, to reflect the communication between human and human as well as human and nature. The view of "free communication" is established based on the abovementioned two aspects. In the opinion of Mozi, the realization of "free communication" must by virtue of the means of "thrift" and "use". Free "communication" requires eliminating class differences as for human and human, to realize equal and free communication; it shall be reflected the harmony between human and nature in terms of human and nature.

\section{TAOIST DESIGN ETHICS}

Taoist thinking is negative and unpretentious. Viewing from the perspective of modern design, Taoist design ethics system is mainly reflected as showing respect for nature. In aesthetic, it is required to grasp the subtle relationship between big aspects and details through learning and imitating the nature, and advocates to realize by comparison, playing a positive role in cultivation modern designers. "Human follows the earth, earth follows haven, haven follows Tao, and Tao follows nature." Taoism advocates harmony between human and nature, which respects the nature the most. The "beauty" meeting the standard of "Tao" is the beauty believed by the Taoism. Later, Zhuangzi summarized it as "heaven and earth have great beauty without words." This thought has played very important role in ancient landscape design and architectural design. Chinese gardens are the treasures in the world garden art. Pursuit of natural beauty is its greatest artistic characteristics, taking simulating nature as its purpose to combine the natural or the artificially modified landscapes, plants and buildings organically, and to make reasonable combination of various parts of the whole building, integrating artificial environment and natural scenery, to form the concentrated aesthetic. Emperor Qianlong of Qing Dynasty has been concluded the following tips to guide gardening: determine the depth due to its height, build the garden near the mountain and by the river, the phase shall be appropriate to the local circumstances and construct the pavilions. Chinese garden designers know how to use the nature to transform the environment into practical scene. Taoism advocates natural beauty and is good at analyze the morphological characteristics of the nature, for example, "the most perfect thing seems like defective, but its function is inexhaustible; the most plentiful thing seems like void, but its role is endless. the most honest thing seems like bending, the most clever thing seems like most awkward one, and the most remarkable eloquence seems like not good with words. A kind of simple and practical "simple beauty" is filled in the design works, which is the main reflection of Taoism's influence on Chinese ancient creation. And it is implicative and restraining, containing profound knowledge, but it is superficially simple, which is also the main performance of Taoism.

Taoist aesthetics not only pursues "simple beauty", but also stresses the "beauty of details", just as what Zhuangzi said, "if everything in the world is small, then the Mount Tai seems small too; the longest living ones are the infants who die at the time they are born, even Peng $\mathrm{Zu}$ lived eight hundred years, he is short-lived". Taoism civilization advocates "big", but pays attention to the details. In essence, there is no difference between big and small in ancient creation design. Momentum can be reflected through big things, and small things reflect the designers' good intentions. Details can reflect the skills of creation better. Craftsmen deliberately carve the details in the creation process, but still hide the beauty of details in the overall beauty of the great nature, making details conform to the whole. "Simple beauty" and "beauty of details" has been given to the ultimate performance in Chinese arts and crafts.

\section{CONCLUSION}

The reason and strength of traditional culture's continuation comes from ethical thought. The deep part and foundation of traditional design culture is formed by traditional design ethics. The important carrier of culture is also attached to traditional thoughts, and the specific ideology of traditional ideology and culture is summation of ethic relation and ethic spirit based on social practice. The learning of traditional ethics and morals of design is conducive of human's long-term development, among which, many aspects require dealing with the relationship between human design and society and nature. In traditional Chinese design, master teaches apprentices in the form of oral. Although there is no specific design theory, it reflects traditional Chinese philosophy's influences in the design. Many of its theories is worthy of reference by modern design, which can promote the perfection of modern design moral construction with profound significance. 


\section{REFERENCES}

[1] Modern Chinese Dictionary , Dictionary Editorial Office, Language Institute of Chinese Academy of Social Sciences, Commercial Press, 2005-6-1

[2] Germany, Moritz $•$ Strock, Ethical Issues

[3] Jiang Songrong. "Research on the Fourth Principle-Design Ethics"

[4] Xu Ping. Caring and Responsibility---Artistic Design as Social Ethics Guide and Its Education, Art Observation, 1998 (8)

[5] Victor Papanek, Design for the Real World

[6] Herbert Spencer, translated by Liu Shuang. Responsibility of Design Profession, Design Gospel, 2010

[7] Lu Xiaobo. Reflection on Design Ethics Issues, Art Observation, 20036

[8] Cui Dahua. Taoism and Chinese Cultural Spirit, Zhengzhou, Henan People's Publishing House, 2003,271

[9] Li Chaode. Design Aesthetics, Hefei: Anhui Fine Arts Publishing House, 2004, 60 . 